\title{
Acquisition of English Collocations through Productive Skills-Analysis of Translation Errors
}

\author{
Frane Malenica ${ }^{1} \&$ Emilija Mustapić ${ }^{2}$ \\ ${ }^{1}$ University of Zadar, English Department, Croatia \\ ${ }^{2}$ Karlovac University of Applied Sciences, Croatia \\ Correspondence: Frane Malenica, University of Zadar, Obala kralja Petra Krešimira IV/2, 23000 Zadar, Croatia. \\ Tel: 385-23-200-713. E-mail: fmalenica@gmail.com
}

Received: June 17, 2015 Accepted: July 4, 2015 Online Published: July 30, 2015

doi:10.5539/ijel.v5n4p42

URL: http://dx.doi.org/10.5539/ijel.v5n4p42

\begin{abstract}
Even though the number of studies focused on English collocations has proliferated in the past twenty years, there is still considerable disagreement over a single unitary definition of collocations (Leśniewska, 2006, p. 1; Barfield \& Gyllstad, 2009, p. 23), which is why the distinction between collocations, idioms and free word combinations is relatively blurry. Collocations play a major role in foreign language acquisition as they increase the language proficiency of the speaker. This paper is a continuation of the research on acquisition of English collocations as a part of an LSP course, conducted among the native speakers of Croatian in June 2013. The conducted analysis was intended to determine to what extent the general English language proficiency affects the knowledge of collocations in the LSP and how and to which extent the congruence of collocations affects the types of errors in translation tasks. Since the previous research showed that productive (translation) tasks pose a bigger challenge for language acquirers than receptive skills (Mustapić \& Malenica, 2013), this paper has provided a detailed analysis of translation errors. The results show a need for didactic improvements in terms of new teaching materials and exercises that would develop productive skills and facilitate acquisition of collocations, both in general language and language for specific purposes.
\end{abstract}

Keywords: collocations, congruence, Error Analysis, productive skills

\section{Introduction}

Since successful utilization of collocation patterns makes a difference between native-like and unnatural-sounding utterances, it should come as no surprise that collocations are regarded as one of the crucial issues for intermediate and advanced levels of foreign language learning. Successful implementation of collocation pairs allows the speakers to convey their ideas and opinions on a particular topic without a decrease in fluency or verity of the message being conveyed (Nesselhauf, 2003; 2005). The results of the previous research conducted with the group of participants used in this research indicate that collocation tasks involving productive skills represent a bigger obstacle for foreign language learners and result in more errors (Mustapić \& Malenica, 2013). Our aim in this paper is to provide an additional perspective on acquisition of collocations using the Error Analysis (EA) methodology and taxonomy proposed by James 1998, and answer the following research questions:

1) What are the typical types of errors committed by foreign language learners?

2) What is the correlation between general language proficiency and error types?

3) What effect does collocation congruence in L1 and L2 have on error types?

\section{Previous Research}

It has been acknowledged that the issue of acquiring collocation-related skills lies in the fact that conventionality is considered to be one of the chief reasons why certain pairs of words are deemed acceptable while others are not, i.e. that it is impossible to judge the grammaticality of these constructions based on their structure alone (Van der Meer, 1998, pp. 316-317). Therein lies the reason why foreign language learners opt for a L1-to-L2 correspondence both as a strategy for storing newly acquired collocations in the mental lexicon and as a strategy for producing certain complex combinations of words that they are not familiar with (Eyckmans, 2009, p. 139). 
This strategy is in line with the claims that the words (or word combinations) heard for the first time are parsed into their constituents and their meaning is analyzed as a sum of those individual constituents, while words with higher frequency are stored as fixed units and retrieved the same way (Booij, 2007, pp. 249-251). There are also claims that this reflects the difference between native speakers who make use of the so-called "idiom principle" for parsing collocations, which implies they perceive and use them as pre-constructed combinations of words, while the foreign language learners use individual elements (Sinclair, 1987, p. 110).

And while this approach yields relatively good results with collocations congruent in the two languages in question, it, quite understandably so, has an adverse effect with non-congruent collocations. While collocations are distributed according to their congruency into either congruent, partially congruent and non-congruent or simply congruent and non-congruent (Nesselhauf, 2003; Revier, 2009; Korhonen, 2007; Stojić \& Murica, 2010), the fact remains that it is generally those collocations that cannot be directly translated from L1 into L2, i.e. the non-congruent ones, that pose a bigger obstacle for foreign language learners.

Mastering the collocation patterns requires a prolonged exposure to a language, which is why numerous studies reveal deficiency in learner's knowledge of collocations, and a significant portion of these gaps can be attributed to L1 influence (among others Nesselhauf, 2003; Gilquin, 2007; Sadeghi, 2009; Granger, 1998; Schmitt, 1998). Because of this, teaching collocations should be an integral part of every language course (Lewis, 2000, p. 8).

However, foreign language learners are bound to produce errors as they are a natural part of language learning, especially lexical errors, which can be particularly disruptive as they can result in a completely or partially wrong message being conveyed by the speakers (Hemchua \& Schmitt, 2006, pp. 3-4). At this point, an important distinction should be made between errors and mistakes. Errors represent production of ungrammatical utterances (written or oral) which reveal gaps in language competence and indicate that a certain rule or pattern in a language had not been mastered by the speaker, while mistakes represent occasional lapses as a result of poor language performance by the speaker (Ellis, 2003, pp.15-18). In other words, mistakes are sporadic while errors are systematic and, as such, pose a much more revealing area of linguistic study, both at the level of an individual learner, or at the level of a particular group.

As an approach to the study of learner language, Error Analysis has been focussed on identifying and analyzing these systematic deviations as a window into the mind of learners. According to Corder, learner errors serve a threefold function - they allow the teachers to see the parts of language study that their students are deficient in, they provide the researchers with evidence about the way languages are acquired or learned, and they serve as a good way for learners to acquire the rules of a language by distinguishing between acceptable and unacceptable utterances (1967, quoted in Ellis \& Barkhuizen, 2005). In Corder's view, there are two major perspectives on learner errors. According to one, the occurrence of errors reflects the deficiencies of the present teaching methods and techniques, that is, it claims that if the methodology was perfect, the errors would not have occurred at all. The second perspective sees errors as an inevitable part of living in an imperfect world and is focused on methods for dealing with errors after they occur. One of the major effects of EA has been the shift from "a preoccupation with teaching towards a study of learning" (Corder, 1982, p. 6).

Before conducting the Error Analysis, the initial step is to define the term error itself, that is, to decide whether we take grammaticality or acceptability of the utterance as the criterion. The safest option would seem to be to define it in terms of grammaticality, i.e. as a "breach of the code" (James, 1998, pp. 62-65). The subsequent analysis should involve the following steps - collecting the sample, identifying the errors, categorizing and describing the errors, analyzing them and explaining their source, evaluating their severity and remediating them with the learners (Ellis \& Barkhuizen, 2005; Gass \& Selinker, 2008).

Errors are traditionally divided into interlingual and intralingual. The former includes transfer and borrowing from L1, while intralingual errors include overgeneralization, misanalysis, incomplete rule application, exploiting redundancy, and system simplification (James, 1998; Ellis \& Barkhuizen, 2005). In terms of surface structure taxonomy, Dulay, Burt, \& Krashen 1982 categorize errors as omissions, additions, misformations, and misorderings, while James (1998) also adds blends to the list of these surface structure errors.

Lexical errors are divided by James (1998) according to their formal and semantic features. Formal errors include formal misselection (wrong choice of affixes, vowels, consonants), misformations (borrowings, coinages, and calques) and distortions (omission, overinclusion, misselection, misordering, blending). Semantic errors include confusion of sense relations (mixing hyponyms and hypernyms, using inappropriate co-hyponyms) and collocation errors (Note 1). Since the main topic of this work are collocations, which represent an important part of the lexicon, this classification will be adopted in this work. 
While EA represents a step forward from perspectives on learner language that appeared before it, its major problems were its focus on errors alone and the problem of defining the proper classification of errors (Gass \& Selinker, 2008, pp. 102-110). Despite EA being able to provide proofs of deficiency in learner's knowledge, it alone cannot provide completely detailed insight into their proficiency as learners can avoid constructions they are uncomfortable or unfamiliar with as a low-risk strategy in order to avoid making mistakes, which would result in their production having very few errors and would indicate a false level of proficiency (Lennon, 2008, pp. 60-63). However, despite the fact that EA has been somewhat abandoned in favour of other approaches, studying errors in the scope of SLA still has its benefits and can provide valuable input in terms of areas of language teaching that should be focused on.

\section{Methodology}

The sample used for the purpose of this study involved 52 participants, the students of the Professional Studies of Hospitality at the Karlovac University of Applied Sciences. They were given 20 collocation translation cloze tasks each, which amounted to a total of 1040 tasks. Each task included a sentence from which the collocation had been omitted with its Croatian equivalent given in the brackets. The tasks in question were a part of a previous research (Mustapić \& Malenica, 2013) which included 60 collocation tasks distributed into 3 types: multiple-choice tasks, the CONTRIX tasks, and translation cloze tasks. CONTRIX task, which was proposed by Revier 2009, is a cloze task with a sentence prompt and a matrix with three columns (in the original version), each containing several members of one word class (verb, noun, article, preposition etc.). The learner has to choose a single member of each column to create a collocation that fits the context of the sentence in question. As Revier admits, it is likely to be perceived as a receptive type of task (2009, p. 129), although this type of exercises also requires the speaker to actively use its productive lexical knowledge. Since the errors committed in the translation cloze tasks could give a better insight into the mechanisms employed by the participants to process and retrieve collocations, this type of task was further analyzed into more detail and the results of the analysis in question are given in this research. Out of 20 tasks selected for the purpose of this work, ten included collocations congruent in English and Croatian, and ten involved used non-congruent collocations. Collocations were taken from their course books and the testing was administered at the end of the academic year.

The participants were also given a general proficiency test and were accordingly distributed into higher and lower general proficiency students. The purpose of this proficiency test was to determine the correlation between general proficiency and collocation proficiency in the initial research, and the correlation between general proficiency and the types of errors. The results of the previous research conducted with this sample showed the influence of congruence of collocations is more prominent among learners with lower general proficiency and that the students with lower proficiency tend to have more difficulties with productive tasks (Mustapic \& Malenica, 2013). The aim of the analysis presented here is to analyse the errors made by the participants in order to find the level and the source of the obstacle posed by collocations and provide suggestions for further didactic improvements.

Even though higher proficiency levels naturally lead to higher level of lexical skills, the relationship between the two is not always so clear-cut and some studies report cases with higher proficiency participants making more errors at the lexical level, or taking the "low-risk route" in terms of choosing a near synonym for a word they are not familiar with (Martin, 1984; Hemchua \& Schmitt, 2006). Kellerman's (1986) study showed that learners are more prone to using L1 transfer in structures with literal meaning, while they are less inclined to do so with idiomatic or metaphorical constructions.

\section{Results and Discussion}

According to the results of the general proficiency test, the participants of this research were divided into lower and higher proficiency language learners, with the former group comprising 25 participants and the latter comprising 27 participants. Out of total 1040 tasks, 122 got a completely correct answer, 416 tasks were left unanswered, while 502 tasks $(48.27 \%)$ included at least one type of error, with some tasks comprising two or more errors at the same time, thus giving a total tally of 554 errors. When we compared the number of errors with the proficiency level, we got a slightly controversial result - the higher proficiency participants produced more errors than the lower proficiency participants (326 compared to 228) and this fact cannot be explained by the group size as the difference between the two groups was marginal. While unexpected at first glance, this information needs to be compared with the number of unanswered tasks for the two proficiency levels as the tendency for avoidance as error-reduction strategy was more notable among the lower proficiency participants $(52.60 \%$ of all tasks left unanswered) than higher proficiency participants (33.26\% of all tasks left unanswered). 
On the other hand, the number of correct answers provided by the participants is in line with what might be expected from each proficiency level as the higher proficiency group provided significantly more correct answers $(20.22 \%)$ than the lower proficiency group (5.80\%) (Figure 1). Thus, even though higher proficiency participants account for more errors, those errors are a result of taking more chances in their language production, i.e. opting for creativity rather than avoidance. According to Lennon 2008, strategies of L2 learning include different cognitive efforts by the foreign language learners to simplify the linguistic structures they are faced with. These may involve ignoring some nuances of meaning or opting for a simpler structure rather than a complex one. In case of participants in this study, these strategies are manifested in choosing (and overrelying on) the direct L1-to-L2 equivalence as the basic strategy and avoiding giving an answer at all, particularly among the more obscure collocations, as will be noted later.

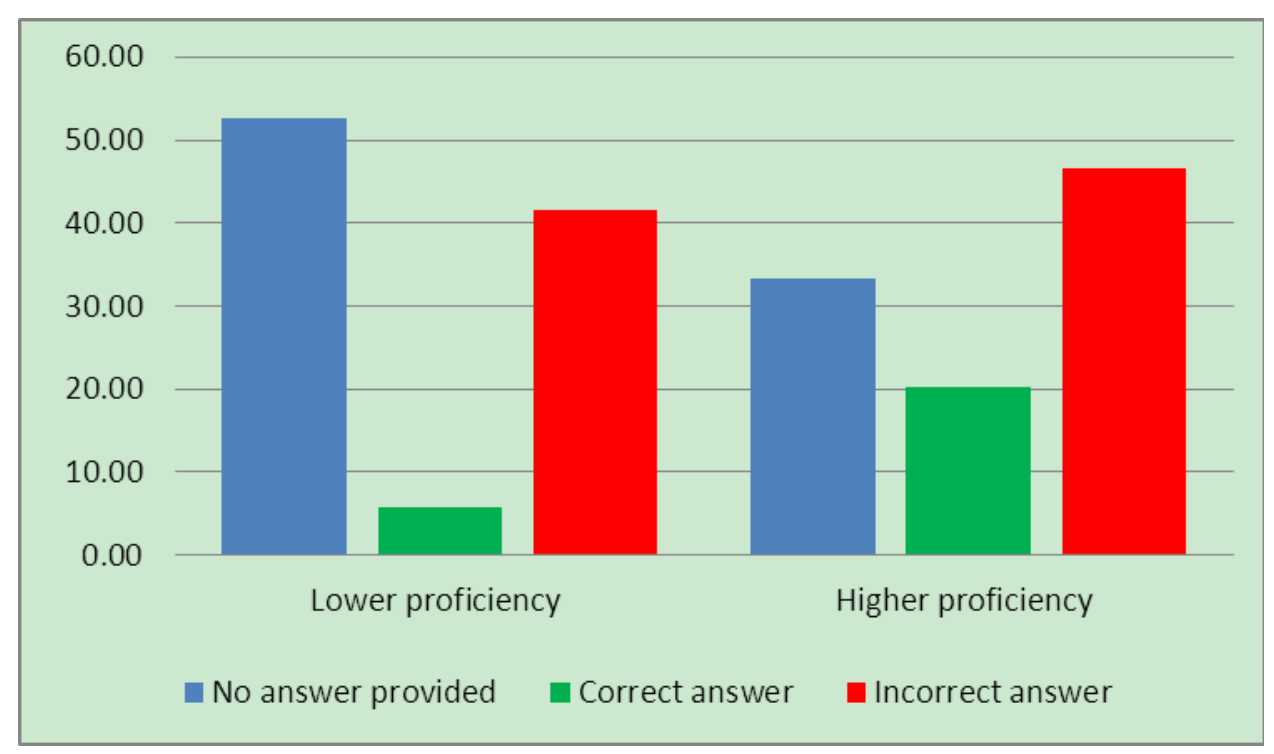

Figure 1. Distribution of correct, incorrect and unanswered tasks per proficiency level

In accordance with James's taxonomy, the errors noted in the corpus of this research are divided into formal errors, which are represented by cases of formal misselection, borrowing, calque, coinage, misordering, omission, and overinclusion; and semantic errors, which are only attested by collocation errors, most notably semantically determined word selection and only just two cases of arbitrary combinations of words (Table 1).

Table 1. Error types and examples

\begin{tabular}{lll}
\hline Formal & Example & Correct form \\
\hline formal misselection & *spend a fourtune & spend a fortune \\
borrowing & *go in to the bankrot & go into bankruptcy \\
calque & *earn money for life & make a living \\
coinage & *spend reachness & spend a fortune \\
omission & *make decision & make a decision \\
overinclusion & *take an advantage & take advantage \\
Semantic & & \\
collocation - word selection & *labour experience & work experience \\
collocation - arbitrary combinations & *laundering money & money laundering \\
\hline
\end{tabular}

Another somewhat unexpected result is the distribution of errors across the two proficiency groups. As the Table 2 indicates, formal errors are more common both at the overall level and among the two participant groups, which indicates there are no major differences in the ratio of errors committed, while there are some interesting differences within certain error subcategories. While the misformations are the most common type of formal errors for both groups and make up an almost identical share of errors in the two groups of participants $(23.25 \%$ and $23.93 \%)$, calques are slightly more notable among the higher than lower proficiency participants $(19.30 \%$ 
and $22.39 \%$, respectively) and we find this to be connected to congruence of collocations and strategies related to it, which are discussed further below. Another notable difference between the two groups can be noted for omissions, which are more prominent among the lower proficiency participants $(17.98 \%$ vs. $13.80 \%)$, which can be attributed to the mentioned tendency for a low-risk strategy with regards to choosing a simpler form so as not to produce an erroneous utterance. It should also be noted that the collocations which involve an article (such as make a decision, conduct a survey, spend a fortune etc.) posed a particular problem for both groups of participants in terms of omission.

Table 2. Distribution of error types according to general language proficiency

\begin{tabular}{llll}
\hline Formal & Total (\%) & Lower proficiency & Higher proficiency \\
\hline formal misselection & 15.34 & 13.60 & 16.56 \\
borrowing & 0.36 & 0.44 & 0.31 \\
calque & 21.30 & 19.30 & 22.39 \\
coinage & 2.89 & 3.51 & 1.23 \\
omission & 15.52 & 17.98 & 13.80 \\
overinclusion & 1.62 & 1.32 & 3.99 \\
\hline Semantic & & & 41.41 \\
\hline collocation error - word selection & 42.60 & 43.42 & 0.31 \\
\hline collocation error - arbitrary combinations & 0.36 & 0.44 & \\
\hline
\end{tabular}

As noted earlier, the share of collocation errors is similar for both groups of participants. The distinction between calques and word selection errors can be hard to draw as one could argue that the former are a subtype of the latter due to the fact that both involve wrong selection of words. However, we have opted to treat these two types of errors as separate in the scope of this work and we believe the two types should be analyzed separately in general, with the difference between the two being the fact that calques are influenced by L1 while semantic collocation errors are not. Thus, a construction like washing money was regarded as a calque as it is a direct translation of the Croatian equivalent collocation pranje novca, while an answer like start a research is considered to be an example of misused combination of words (albeit not ungrammatical) with no L1 influence.

The distinction between calques and semantic errors is related to another property of collocations that was analyzed in this work - their congruence in L1 and L2. As mentioned earlier, only those collocations which can be directly translated from L1 into L2 were regarded as congruent. When comparing the share of errors among congruent and non-congruent collocations (Table 3), it is worth noting that almost all error types are more prominent among congruent collocations, except for calques. This is explained by the fact that the participants opted not to provide an answer when dealing with non-congruent collocations in twice as many tasks as with congruent collocations and this was more prominent with the group of lower proficiency participants (see below). Such a high proportion of avoided tasks is not particularly surprising considering the tendency of language learners to avoid obscure word combinations (Leśniewska, 2006) and considering the results mentioned earlier. On the other hand, calques being more prominent among non-congruent collocations should be regarded as a result of employing L1 transfer as a strategy for minimizing the effort needed to process and/or produce a certain lexical item. While the benefits of L1 transfer in terms of facilitation of learning through use of lexical similarities between certain languages are numerous, language learners have to be very cautious with its application so as not to become overly reliant on it.

Examples of calques among non-congruent collocations found in our research are *earn for living (make a living), *start the question (raise the question), *check without cover (bad check), speed up with *conclusions (jump to conclusions). 
Table 3. Distribution of error types according to congruence of collocations

\begin{tabular}{llll}
\hline Formal & Total (\%) & Congruent (\%) & Non-congruent (\%) \\
\hline formal misselection & 15.34 & 13.18 & 2.17 \\
borrowing & 0.36 & 0.36 & 0.00 \\
calque & 21.30 & 6.14 & 15.16 \\
coinage & 2.89 & 1.81 & 1.08 \\
omission & 15.52 & 8.66 & 6.86 \\
overinclusion & 1.62 & 0.54 & 1.08 \\
\hline Semantic & & & \\
\hline collocation - word selection & 42.60 & 25.27 & 17.33 \\
collocation - arbitrary combinations & 0.36 & 0.36 & 0.00 \\
\hline
\end{tabular}

When we compare the data for congruence among the semantic errors with general proficiency, we can note that the difference between congruent and non-congruent collocations is more prominent among the lower proficiency participants $(29.39 \%$ vs. $14.37 \%)$ than among the higher proficiency participants $(24.23 \%$ vs. $17.48 \%$ ), which indicates that the higher proficiency participants have somewhat better understanding of where L1 transfer can be applied with success.

\section{Conclusion}

This study aimed to analyze the collocation errors committed by language learners in translation tasks and to test the correlation between congruence of collocations involved and the general language proficiency of the participants. Several results have emerged, some of which were relatively unsurprising, but some of which provided interesting new insights. Even though it was expect that the general proficiency would be in negative correlation with the number of errors, the opposite turned out to be true. However, this was not the case because the lower proficiency participants provided more correct answers (which would, in fact, be quite controversial), but because they opted not to provide an answer to more questions. Of course, the willingness of language learners to participate in studies such as this and possible anxiety over potentially negative results can account for their tendency to avoid providing an answer as well.

However, a direct correlation between general proficiency with collocation proficiency has been established in terms of number of correct answers provided. While no significant difference in the distribution of main types of errors between higher and lower proficiency participants was noted in this research, omissions were more notable among the lower proficiency participants, which can be attributed to the avoidance as a strategy for not committing a mistake. Higher proficiency participants take more risks, and seem to make better use of L1 transfer, although not always with the same level of success as indicated by the slightly higher ratio of calque errors committed by them.

Collocation congruence was analyzed to see the differences in number and type of errors committed for congruent and non-congruent collocations. As was expected, congruent collocations yielded more avoided tasks, which resulted in less erroneous tasks. However, calque errors were found to more numerous with congruent collocations, which represents a result of unsuccessful employment of L1 transfer. This, however, does not imply that calque errors were not or could not have been committed with congruent collocations. Quite the contrary, just because a certain combination of words can be directly translated into L2, it does not mean that another combination which would also represent a direct translation, albeit an unacceptable one, could not be provided and this was also the noted in our research.

Another issue with non-congruent collocations is that it is more difficult for language learners not to perceive such combinations as single units but process them as distinct lexemes than it is with collocations for which they can easily assign an L1 equivalent. An additional problem with non-congruent collocations may lie in their frequency of occurrence, which is an issue that has not been addressed in this paper.

When conducting similar research with collocations and errors manifested in them, we feel it would be of considerable value to also test whether the participants are also familiar with tested collocations in their L1. Another matter that should be addressed is the importance of L1 transfer and the role of language teachers for emphasizing the applicability of transfer as a learning strategy as well as creation of exercises based on corpus data with regards to frequency for improving productive skills with collocations. We believe that by addressing the topic of collocation congruence through a series of translation tasks or similar tasks for productive skills, such as the CONTRIX tasks (especially with examples based on language corpora), the language learners would 
gain a better insight into how and to which extent L1 transfer can be applied and how to incorporate their knowledge of collocation patterns into their foreign language use.

It should, of course, be admitted that not all of the errors found in the research need necessarily be directly correlated with L1 transfer or proficiency level. However, the differences between particular error types and their correlation to congruence seem to indicate that there is a certain correlation between the two, as well as between error types and general proficiency. Further research analyzing different types of errors across proficiency levels should undoubtedly yield interesting implications for language acquisition and provide very useful information for future improvement of language teaching practice.

\section{References}

Barfield, A., \& Gyllstad, H. (2009). Researching Collocations in Another Language - Multiple Interpretations. London: Palgrave MacMillan. http://dx.doi.org/10.1057/9780230245327

Booij, G. (2007). The Grammar of Words. An Introduction to Morphology. Oxford: OUP. http://dx.doi.org/10.1093/acprof:oso/9780199226245.001.0001

Corder, S. P. (1967). The significance of learners' errors. International Review of Applied Linguistics, 5, 161-170. http://dx.doi.org/10.1515/iral.1967.5.1-4.161

Corder, S. P. (1982). Error Analysis and Interlanguage. Oxford: OUP. http://dx.doi.org/10.1017/S0261444800002822

Dulay, H., Burt, M., \& Krashen, S. (1982). Language Two. New York: OUP.

Ellis, R. (2003). Second Language Acquisition. Oxford: OUP.

Ellis, R., \& Barkhuizen, G. (2005). Analysing Learner Language. Oxford: OUP. http://dx.doi.org/10.1111/j.1473-4192.2007.00140.x

Eyckmans, J. (2009). Toward an Assessment of Learner's Receptive and Productive Syntagmatic Knowledge. In A. Barfield \& H. Gyllstad (Eds.), Researching Collocations in Another Language. London: Palgrave MacMillan. http://dx.doi.org/10.1057/9780230245327

Gass, S. M., \& Selinker, L. (2008). Second Language Acquisition: An Introductory Course (3rd ed.). New York/London: Routledge. http://dx.doi.org/10.4324/9780203932841

Gilquin, G. (2007). To err is not all. What corpus and elicitation can reveal about the use of collocations by learners. Zeitschrift für Anglistik und Amerikanistik, 55(3), 273-291. http://dx.doi.org/10.1515/zaa.2007.55.3.273

Granger, S. (1998). Prefabricated patterns in advanced EFL writing: Collocations and lexical phrases. In A. P. Cowie (Ed.), Phraseology: Theory, Analysis and Applications (pp. 145-160). Oxford: Clarendon Press.

Hemchua, S., \& Schmitt, N. (2006). An analysis of lexical errors in the English compositions of Thai learners. Prospect, 21(3), 3-25.

James, C. (1998). Errors in language learning and use: Exploring error analysis. New York: Longman. http://dx.doi.org/10.4324/9781315842912

Kellerman, E., \& Sharwood Smith, M. (Eds.). (1986). Cross-linguistic Influence in Second Language Acquisition. Oxford: Pergamon Press.

Korhonen, J. (2007). Probleme der kontrastiven Phraseologie. In Burger et al. (Eds.), Phraseologie. Ein internationals Handbuch zeitgenössische Forschung (pp. 574-589). Berlin, New York: de Gruyter. http://dx.doi.org/10.1515/9783110912494.117

Lennon, P. (2008). Contrastive Analysis, Error Analysis, Interlanguage. In S. Gramley \& V. Gramley (Eds.), Bielefeld Introduction to Applied Linguistics. A Course Book. Bielefeld: Aisthesis Verlag.

Leśniewska, J. (2006). Collocations and second language use. Universitatis Iagellonicae Cracoviensis, 123, 95-10.

Lewis, M. (Ed.). (2000). Teaching collocation: Further developments in the lexical approach. Hove: Language Teaching Publications.

Martin, M. (1984). Advanced vocabulary teaching: The problem of synonyms. The Modern Language Journal, 68, 130-137. http://dx.doi.org/10.1111/j.1540-4781.1984.tb01556.x 
Mustapić, E., \& Malenica, F. (2013). Collocations as a Part of an English LSP Course-The Importance of Congruence for Achieving English Language Proficiency. In P. Vičić, V. M. Ipavec, \& A. Plos (Eds.), Proceedings of the 6th International Language Conference on the Importance of Learning Professional Foreign Languages for Communication between Cultures. University of Maribor, Celje, Slovenija.

Nesselhauf, N. (2003). The use of collocations by advanced learners of English and some implications for teaching, Applied Linguistics, 24(2), 223-242. http://dx.doi.org/10.1093/applin/24.2.223

Nesselhauf, N. (2005). Collocations in a learner corpus, Amsterdam/Philadelphia: John Benjamin Publishing Company. http://dx.doi.org/10.1075/scl.14

Sadeghi, K. (2009). Collocational differences between L1 and L2: Implications for EFL learners and teachers. TESL Canada Journal/Revue TESL du Canada, 26(2), 100-124.

Schmitt, N. (1998). Measuring collocational knowledge: Key issues and experimental assessment procedure. International Review of Applied Linguistics, 119-247.

Sinclair, J. (1987). Collocation: a progress report. In R. Steele \& T. Threadgold (Eds.), Language Topics. Essays in honour of Michael Halliday (Vol. II, pp. 319-331). Amsterdam \& Philadelphia: John Benjamins. http://dx.doi.org/10.1075/z.lt2.03ste

Stojić, A., \& Murica, S. (2010). Kolokacije - teorijska razmatranja i primjena u praksi na primjerima iz hrvatskoga i njemačkoga jezika. Fluminensia: časopis za filološka istraživanja, 22(2), 111-125.

Van der Meer, G. (1998). Collocations as one particular type of conventional word combinations. Their definition and character. EURALEX '98 Proceedings I-II, Papers submitted to the Eighth EU-RALEX International Congress on Lexicography in Liège, Belgium, 1, 313-322.

\section{Note}

Note 1. For a more detailed overview of each error type, see James, 1998; Hemchua \& Schmitt, 2006.

\section{Copyrights}

Copyright for this article is retained by the author(s), with first publication rights granted to the journal.

This is an open-access article distributed under the terms and conditions of the Creative Commons Attribution license (http://creativecommons.org/licenses/by/3.0/). 